\title{
La concepción moderna de felicidad en Descartes
}

Marvin Sebastián Estrada López

Universidad del Norte, Colombia 


\title{
La concepción moderna de felicidad en Descartes*
}

Resumen: en este artículo se muestra la nueva concepción cartesiana de felicidad y su reforma del modelo eudemonista griego. Principalmente, se resaltan tres cosas. La primera es que la felicidad cartesiana consiste en un estado en que la mente se encuentra tanto contenta como satisfecha. Descartes no considera que la felicidad sea un bien, sino que es el placer que gozamos cuando alcanzamos el bien supremo. Por eso, la segunda cosa que vale la pena notar es que la felicidad, para Descartes, no ocupa el lugar del bien supremo. Finalmente, la tercera cosa que quiero señalar es que Descartes propone dos fines para nuestras acciones. Para examinar los cambios propuestos por esa reforma, prestaré especial atención a los tres puntos mencionados. Finalmente, mostraré cómo Descartes interpreta favorablemente las teorías de Aristóteles, Zenón y Epicuro, siguiendo su nuevo modelo.

Palabras clave: felicidad, bien supremo, virtud, placer, fin de nuestras acciones.

\section{Descartes's modern conception of happiness}

\begin{abstract}
I want to show Descartes's new conception of happiness and his reformulation of the Greek eudaemonist model. I want to highlight three features of the Cartesian theory of happiness. First, Cartesian happiness is not a good but the pleasure we enjoy when we possess the highest good. Second, Cartesian happiness is not our highest good. Third, Descartes identifies two ends for our actions. These three features establish an important distance between the Greek tradition and the Cartesian theory of happiness. To examine the changes Descartes introduces in his analysis of happiness, I will center my exposition in these three features. Finally, I will show how Descartes interprets the ancient theories of Aristotle, Zeno and Epicurus.
\end{abstract}

Keywords: happiness, highest good, virtue, pleasure, end of our actions.

Fecha de recepción: 29 de mayo de 2019

Fecha de aceptación: 2 de septiembre de 2019

Forma de citar (APA): Estrada López, M. S. (2020). La concepción moderna de felicidad en Descartes. Revista Filosofía UIS, 19(2), https://doi.org/10.18273/revfil.v19n2-2020003

Forma de citar (Harvard): Estrada López, M. S. (2020). La concepción moderna de felicidad en Descartes. Revista Filosofía UIS, 19(2), 35-54.

Marvin Sebastián Estrada López: colombiano. Magíster en Filosofía. Universidad del Norte, Colombia.

ORCID iD: 0000-0002-1244-5846

Correo electrónico: marvine@uninorte.edu.co; msestradal@gmail.com; marvin.estrada@ ufu.br

*Artículo de reflexión derivado de investigación. 


\section{La concepción moderna de felicidad en Descartes ${ }^{1}$}

\section{Introducción}

La felicidad como tema de reflexión filosófica proviene de la tradición griega antigua. Las importantes discusiones sobre la eudaimonia de filósofos como Platón, Aristóteles, Epicuro y los miembros de la escuela estoica, cuyas raíces están en el pensamiento socrático, marcaron en gran medida las posteriores reflexiones sobre el tema: "its diffused influence on later moral thought is evident in philosophers as different as Hobbes, Spinoza, Descartes, Locke, Butler, Kant, Bentham, Mill, Sidgwick, Hare, Maclntyre, and Williams" (Long, 2006, p. 23). Para la tradición griega, la eudaimonia constituye el fin último de los seres humanos, el último objeto del deseo, aquello que se prefiere por sí mismo y no por alguna otra cosa, el bien supremo (Long, 1996, p. 179). El modelo tradicional presenta la eudaimonia como el bien supremo de los seres humanos y como el fin último de todas sus acciones. Por su parte, Descartes presenta su propia reflexión sobre la felicidad y el bien supremo pensando en una reforma de ese modelo.

En una carta en la que Leibniz pretende hablar libremente del cartesianismo, se propone mostrar lo que Descartes ha tomado de los filósofos antiguos (1880, pp. 297-298). Para el filósofo alemán, el pensamiento moral de Descartes solo era "un composé des sentimens des Stoïciens et des Epicuriens, ce qui n'est pas fort difficile, car Sénèque déjà les concilioit fort bien" (p. 298). En general, Leibniz afirmaba que solo bastaba "voir l'incomparable manuel d'Epictete et l'Epicure de Laërce ${ }^{2}$ pour avouer que des Cartes n'a pas avancé la practique de la morale" (p. 298). Para este filósofo alemán, Descartes solo toma algunos elementos de cada

\footnotetext{
${ }^{1}$ Este artículo es una versión modificada del primer capítulo de mi disertación de maestría, titulada "A felicidade cartesiana", desarrollada en la Universidade Federal de Uberlândia y financiada por la Coordenação de Aperfeiçoamento de Pessoal de Nível Superior (CAPES). Agradezco a las dos instituciones por el apoyo para realizar este trabajo.

${ }^{2}$ Leibniz aquí hace referencia al libro $\mathrm{X}$ de la obra de Diógenes Laercio, Vidas y opiniones de los filósofos ilustres, dedicado a la figura y al pensamiento de Epicuro.
} 
una de las principales doctrinas morales de los antiguos para intentar conciliarlas de una forma coherente, lo que no era ninguna novedad en la época ${ }^{3}$.

Tanto Descartes como los filósofos griegos aseguran que la filosofía puede enseñarnos a vivir bien (Cottingham, 1998, p. 5). También es verdad que Descartes mantiene el interés en los conceptos tradicionales de felicidad y virtud (Marshall, 1998, p. 61) y que propone una interpretación favorable que concilia las principales doctrinas de los antiguos. Pero ese interés persistente en las cuestiones tradicionales no impide la posibilidad de avance del estudio de Descartes sobre las relaciones entre virtud y felicidad: "continuidad no significa repetición" (Faye, 1998, p. 300). Esa conciliación cartesiana de las teorías antiguas sobre la felicidad, que Leibniz menospreciaba, solamente es posible gracias a una cuidadosa reconsideración de esos temas tradicionales introduciendo una nueva concepción de felicidad que está ligada a una nueva forma de configurar el modelo eudemonista antiguo, basada en una nueva forma de entender la naturaleza humana. Por eso, la filosofía cartesiana ofrece mucho más que una simple reunión de elementos morales antiguos.

En este artículo se muestra la nueva concepción cartesiana de felicidad y su reforma del modelo griego. Principalmente, se resaltan tres cosas. La primera es que la felicidad cartesiana consiste en un estado en que la mente se encuentra contenta y satisfecha. Descartes no identifica la felicidad con un tipo particular de vida ni la considera un bien. Para él, la felicidad no es otra cosa que una emoción placentera de la mente. Es verdad que la felicidad está íntimamente unida con la práctica de la virtud, pero estas, para Descartes, no son la misma cosa. La felicidad realmente es el contento o la satisfacción del alma generados por el ejercicio de la virtud, el bien supremo. La segunda cosa que vale la pena notar es que la felicidad, para Descartes, no ocupa el lugar del bien supremo; sin embargo, ella puede ser considerada, junto con la virtud, como el fin de nuestras acciones. Finalmente, la tercera cosa que se resalta es que Descartes propone dos fines para nuestras acciones.

Si se tienen en cuenta esos tres aspectos, no es difícil aceptar que la concepción cartesiana de felicidad se aleja de la tradición ética griega. En este artículo se señala cómo la teoría cartesiana de felicidad ofrece una reforma del modelo tradicional. Para examinar los cambios propuestos por esa reforma, se prestará especial atención a los tres puntos mencionados anteriormente. Por último, se mostrará cómo Descartes, con su nuevo modelo, interpreta favorablemente las teorías de Aristóteles, Zenón y Epicuro.

\footnotetext{
3 Por ejemplo, Pierre Charron (1541-1603) "mêle à des élèments stö̈ciens, issus de Du Vair et Montaigne une bonne dose d'épicurisme entendu au meilleur sens, Dieu étant l'auteur du plaisir naturel et modéré" (Rodis-Lewis, 1997, p. 110). Faye (1998) ofrece un interesante estudio sobre la influencia de Charron sobre Descartes.
} 


\section{El punto de partida}

A mediados de mayo de 1645, Descartes, preocupado por algunos problemas de salud de la Princesa Élisabeth, inicia una presentación, por medio del intercambio epistolar que mantenían, de una serie de remedios para superar la tristeza de la melancólica princesa de Bohemia, la cual se manifestaba en forma de una "fièvre lente" (Descartes a Élisabeth, Egmond, 18 mai 1645. AT IV, 201). Descartes consideraba que esa fiebre era producto de una emoción de tristeza y que para curar la enfermedad física era necesario eliminar esa emoción negativa ${ }^{4}$. Por eso, Descartes decide introducir una discusión sobre "des moyens que la philosophie nous enseigne pour acquérir cette souveraine félicité" (Descartes à Élisabeth, Egmond, 21 juillet 1645. AT IV, 252). Como punto de partida, Descartes propone la lectura de De vita beata de Séneca porque, según él, uno de los medios más útiles para desarrollar la discusión consiste en "examiner ce que les anciens ont écrit" sobre el tema de la felicidad e intentar ir más allá de lo que ellos propusieron "en ajoutant quelque chose à leur préceptes" (AT IV, 252). Así, dice Descartes, tanto él como la Princesa podrían apropiarse de esos preceptos y "se disposer à les mettre en pratique" (AT IV, 252).

Este examen de las teorías antiguas sobre la felicidad es el punto de partida de un proceso cuyo objetivo será tener la capacidad de actuar como conviene para alcanzar la felicidad suprema. Tomar ese punto de partida es aceptar la forma tradicional de entender los objetivos de la teoría ética (Sorell, 1993, p. 276). Pero en el desarrollo de ese proceso de examen, Descartes consideró que era necesario superar lo ya dicho por los antiguos y descubrir algo nuevo que se incorporara a lo establecido por la filosofía tradicional. De esta forma, sería posible adoptar nuevos preceptos que conducirían la acción apropiada para alcanzar la felicidad ${ }^{5}$. Se trata de un proceso en el que Descartes tratará de "préciser les fondements de doctrines assez vagues" (Rodis-Lewis, 1998, p. 43) y le permitirá adoptar y poner en práctica nuevos preceptos ${ }^{6}$.

\section{La béatitude cartesiana}

Sin embargo, la lectura de De vita beata no dio los resultados esperados por el filósofo francés. Descartes considera que la forma en que Séneca expone el tema de la felicidad no es "assez exacte pour mériter d'être suivie" (Descartes

\footnotetext{
${ }^{4}$ Tristeza causada, dice Descartes, por los infortunios sufridos por la familia de Élisabeth desde 1620, cuando su padre perdió el trono de Bohemia y comenzó su vida en el exilio (Descartes a Élisabeth, Egmond, 18 mai 1645. AT IV, 201).

${ }^{5}$ En el Discurso del método, Descartes anhelaba una reforma de las enseñanzas de los antiguos paganos sobre las costumbres. Él las comparaba con "palacios muy soberbios y magníficos, construidos solo sobre arena y barro" (AT VI, 8).

${ }^{6}$ Preceptos que serán expuestos en la carta a Élisabeth del 4 de agosto de 1645 (AT IV, 265-266).
} 
a Élisabeth, Egmond, 4 août 1645. AT IV, 263). Por eso, lo que inicialmente fue anunciado como una revisión de la obra de Séneca, se volvió rápidamente una exposición de las propias ideas de Descartes.

El filósofo francés considera, como Séneca, que todos los hombres desean ser felices (Descartes a Élisabeth, Egmond, 4 août 1645. AT IV, 263). También piensa, al igual que el filósofo romano, que los hombres no saben determinar correctamente lo que es la felicidad ${ }^{7}$. Por eso, la primera cosa que Descartes debe aclarar es su definición de felicidad. Descartes pensaba que tenía "something new to say about happiness" (Schneewind, 1998, p. 189). Para él, la felicidad o "béatitude" 8 consiste en "un parfait contentement d'esprit et une satisfaction intérieure" (Descartes a Élisabeth, Egmond, 4 août 1645. AT IV, 264) que los sabios adquieren sin el favor de la fortuna. Vivir felizmente, vivere beate, no es otra cosa "qu'avoir l'esprit parfaitement content et satisfait" (AT IV, 264).

Según Descartes, debemos ejercitar la virtud para contentarnos completamente, para lograr la felicidad. Él afirma que para obtener un contento sólido es necesario practicar la virtud, es decir, "d'avoir une volonté ferme et constante d'exécuter tout ce que nous jugerons être le meilleur, et d'employer toute la force de notre entendement à en bien juger" (Descartes a Élisabeth, Egmond, 18 août 1645. AT IV, 277). Descartes es claro cuando afirma que necesariamente la práctica de la virtud conducirá a la felicidad porque no podríamos "jamais pratiquer aucune vertu (c'est-à-dire faire ce que notre raison nous persuade que nous devons faire), que nous n'en recevions de la satisfaction et du plaisir" (Descartes a Élisabeth, Egmond, $1^{\text {er }}$ septembre 1645. AT IV, 284).

La felicidad cartesiana no es otra cosa que un estado placentero de la mente que consiste en el contentamiento producido por la conciencia de haber hecho uso de nuestro mayor bien, la virtud, junto a la satisfacción de haber realizado nuestro mejor esfuerzo y la tranquilidad de saber que no dejamos de hacer nada que estuviera en nuestro poder. La béatitude es el placer que naturalmente acompaña al ejercicio de la virtud, el bien supremo del individuo.

Descartes reconoce que todos los seres humanos tienen como objetivo ser felices. Pero eso no significa que la felicidad sea el bien supremo. Por el contrario, Descartes nota que existe "une différence entre la béatitude, le souverain bien et la dernière fin ou le but auquel doivent tendre nos actions" (Descartes a Élisabeth,

\footnotetext{
"No hay quien no quiera, ioh hermano Galión!, vivir felizmente, pero para ver qué es lo que hace la vida feliz, todos andan ciegos" (Séneca, 1979, p. 407).

${ }^{8}$ Descartes usa este término, que en el siglo XVII hacía referencia a la mayor felicidad (Furetière, 1690), para que su definición de la felicidad verdadera no sea confundida con la dicha (I'heur), término de uso más común y que hace referencia al placer proveniente de la posesión de bienes de la fortuna.
} 
Egmond, 18 août 1645. AT IV, 275) ${ }^{9}$. El bien supremo cartesiano es "I'exercice de la vertu" (Descartes a Élisabeth, Egmond, 6 octobre 1645. AT IV, 305), la excelencia del individuo humano, definida como tener siempre "une ferme et constante résolution de faire exactement toutes les choses que l'on jugera être les meilleures, et d'employer toutes les forces de son esprit à las bien connaître" (Descartes a Christine de Suède, Egmond, 20 novembre 1647. AT V, 83). La felicidad, en la teoría cartesiana, no es el bien supremo, sino que lo presupone. Dicha felicidad es "le contentement ou la satisfaction d'esprit" (Descartes a Élisabeth, Egmond, 18 août 1645. AT IV, 275) que proviene del ejercicio de la virtud, el verdadero bien supremo del individuo. Descartes insiste en señalar que la felicidad consiste en la emoción de contentamiento y la satisfacción que son generadas cuando ponemos en práctica la virtud, cuando logramos la excelencia de nuestra naturaleza. Sin duda, la virtud debe ser puesta como "but en toutes nos actions" (AT IV, 275) porque es el bien de mayor valor que podemos alcanzar. De esa forma, la virtud es vista como el fin último de nuestras acciones. Pero como ella siempre está acompañada por la béatitude, también esa felicidad puede ser considerada como el objetivo de las acciones. Como ella es el premio que recibimos al alcanzar la virtud, Descartes considera que la felicidad también puede ser tomada como el fin último de nuestras acciones.

\section{La ruptura inicial con la tradición eudemonista}

Las primeras cosas que vale la pena notar son las siguientes: para Descartes la felicidad consiste en una emoción de la mente y ella no es el bien supremo. Descartes no define la felicidad como un tipo particular de vida, ni como un tipo particular de acción, ni como el bien supremo. Para él, la felicidad no es otra cosa que una emoción placentera del alma. La felicidad cartesiana realmente es el contentamiento o la satisfacción del alma generados por el ejercicio del bien supremo. Marshall (1998) afirma que Descartes pensaba que la felicidad era "a blend of contentment (a positive affect) and tranquillity (an unperturbed state)" (p. 71, nota 1). Por su parte, Kambouchner (2001) también señala que la felicidad cartesiana no es más que ese contentamiento perfecto del alma o, en otras palabras, una perfecta satisfacción interior (p. 307).

En ese aspecto, la concepción cartesiana de felicidad propone una novedad en relación a la tradición ética griega. Esto era lo que Descartes pretendía: encontrar nuevo conocimiento con el fin de añadirlo a las teorías antiguas, pues esta nueva

\footnotetext{
${ }^{9}$ En esta frase, Descartes no niega que el bien supremo o la felicidad puedan ser el fin último de nuestras acciones. Aquí está proponiendo una revisión del modelo griego evitando asumir que la felicidad es el bien supremo y el fin último. Por eso, Descartes emprende un análisis de cada uno de los conceptos separadamente. Así, por un lado, define la felicidad, por otro, define la virtud, luego, establece la relación entre ellas y finalmente señala que ambas pueden ser consideradas como el fin último de nuestras acciones.
} 
definición de felicidad no es totalmente compatible con el modelo tradicional griego. En ese sentido, Striker (1990) considera que ni Platón ni Aristóteles pensaron que la felicidad misma "consisted in being pleased with one's life" (p. 97) ya que los griegos no usaban el término eudaimon para describir "transient moods or satisfactions" (Long, 1996, p. 181). Esto hace que Striker (1990) afirme que las teorías griegas sobre la felicidad "were not recipes for reaching a certain state of mind" (p. 97).

En dichas teorías griegas, la felicidad consistía en conducir la vida de la mejor forma posible. Si esta interpretación del modelo griego de felicidad es correcta, no es muy difícil ver que la propuesta cartesiana no sigue estrictamente ese modelo. Striker (1990) considera que la felicidad griega es una fórmula para llevar una buena vida. Pero, para Descartes, la felicidad es un "plaisir de l'âme" (Descartes a Élisabeth, Egmond, 6 octobre 1645. AT IV, 309) y no una forma de vida determinada. Es verdad que esa emoción placentera es la recompensa que recibe el individuo que actúa de la mejor forma, pero en la teoría cartesiana, ellas son dos cosas diferentes.

Rutherford (2004) también cree que la presentación que Descartes ofrece de la felicidad como un estado afectivo "breaks decisively with a key assumption of ancient eudaimonism"10 (p. 182). Esa suposición consiste en identificar la felicidad con el bien supremo. Más precisamente, la suposición clave de la tradición griega es pensar la felicidad como un bien. Como Descartes no piensa en la felicidad como un bien, sino como un placer derivado de la posesión del bien supremo, no puede aceptar esa identificación y, así, se aleja del modelo de felicidad antiguo. De hecho, cuando se diferencia la noción de felicidad de la noción de bien supremo, "Descartes lays the foundations of a theory that is distinct from both these ancient views... By contrast, Descartes begins with a different understanding of happiness. For him, 'happiness' means a kind of pleasure" (Rutherford, 2004, p. 182). Las teorías éticas eudemonistas identifican la felicidad con el bien supremo o fin último, ese único bien que se elige por sí mismo y nunca por causa de algún otro bien ${ }^{11}$. El hecho de que Descartes distinga entre felicidad y bien supremo,

\footnotetext{
${ }^{10}$ Cuando uso las expresiones "tradición eudemonista", "teorías antiguas de la felicidad" u otras similares, generalmente estoy haciendo referencia a las teorías de la felicidad de Aristóteles, de los epicureístas y de los estoicos. Estas son las principales teorías que Descartes estudia en su obra y todas ellas trabajan sobre la base de identificar la eudaimonia con el bien supremo y con el fin de nuestras acciones.

${ }^{11}$ Una influyente formulación de esa concepción se encuentra en la Ética Nicomáquea: “llamamos perfecto lo que siempre se elige por sí mismo y nunca por otra cosa. Tal parece ser la felicidad (eudaimonia), pues la elegimos por ella misma y nunca por otra cosa" (Aristóteles, 1097a35-b1). Importantes elementos de la teoría eudemonista son encontrados también en la obra de Platón, especialmente en Eutidemo: "todos deseamos ser felices" (Platón, 1983, 282a) y en Banquete: "los felices son felices, y no es preciso todavía preguntar: ¿y para qué quiere ser feliz aquel que lo quiere? Al contrario, parece que la respuesta tiene su fin" (Platón, 1986, 205a). Aristóteles y los estoicos se apropian de algunos de esos elementos platónicos (Long, 1996, p. 183).
} 
y su presentación de la felicidad, como una emoción que se produce cuando se posee el bien supremo, da cuenta de la distancia entre la teoría moral cartesiana y el eudemonismo clásico (p. 184) $)^{12}$.

Descartes presenta esta distinción entre la felicidad y el bien supremo basado en su comprensión particular del placer. Todo placer o contentamiento es una emoción positiva que se siente en el alma cuando ella considera que tiene un bien o perfección, ya sea por alguna acción del alma misma o por la intervención de procesos corporales (Descartes a Christine de Suède, Egmond, 20 novembre 1647. AT V, 84). Lo que nos hace sentir contentamiento en nuestra alma es "I'opinion qu'elle a de posséder quelque bien" (AT V, 84-85). Todo contentamiento consiste únicamente en "le témoinagne intérieur que nous avons d'avoir quelque perfection" (Descartes a Élisabeth, Egmond, $1^{\text {er }}$ septembre 1645. AT IV, 284). Cuando consideramos que poseemos algún bien o perfección en nosotros, nuestra alma se siente satisfecha y contenta. Esa "consideración del bien presente excita en nosotros la alegría" (Pasiones, a. 61. AT XI, 376), la cual es una "emoción agradable del alma" que consiste en el disfrute que el alma tiene del bien que se representa como propio (Pasiones, a. 91. AT XI, 396). El placer, para Descartes, no es propiamente un bien, sino que es el goce que el alma siente cuando posee algún bien.

Descartes afirma que "chaque plaisir se devrait mesurer par la grandeur de la perfection qui le produit" (Descartes a Élisabeth, Egmond, $1^{\text {er }}$ septembre 1645. AT IV, 284). Así como el placer producido por la posesión de un bien es proporcional al valor de dicho bien, el placer producido por el ejercicio del bien supremo, el bien de mayor valor, debe ser "un plaisir sans comparaison plus doux, plus durable et plus solide que tous ceux qui viennent d'ailleurs" (Descartes a Christine de Suède, Egmond, 20 novembre 1647. AT V, 85). Ese placer superior es la felicidad, el fruto que nuestra alma goza cuando ponemos en práctica la virtud. En el esquema cartesiano, la felicidad es el placer más elevado, "le repos d'esprit et la satisfaction intérieure" (AT V, 85) superior, que solo puede ser disfrutado cuando sabemos que nunca hemos dejado de hacer lo mejor que podemos, es decir, cuando practicamos la virtud, el bien supremo. Para Descartes, la felicidad es el fruto placentero que gozamos cuando poseemos dicho bien supremo.

Así, Descartes cumple su objetivo de añadir algo nuevo a los preceptos antiguos y presenta la primera característica de su reforma del modelo eudemonista

\footnotetext{
${ }^{12}$ Svensson (2015) también cree que la distinción que Descartes establece entre felicidad y el bien supremo marca una distancia entre su teoría de felicidad y la tradición eudemonista. Teniendo en cuenta que, para Descartes, la felicidad es una emoción que proviene del ejercicio del verdadero bien supremo, se puede aceptar que la teoría moral cartesiana no continúa fielmente el modelo tradicional. Por su parte, Shapiro (2011) también considera que la felicidad cartesiana se diferencia del modelo eudemonista tradicional. Ella afirma simplemente que "if we focus simply on the core of the position -that happiness is the highest good- it is hard to claim that Descartes is a eudaimonist" (p. 14).
} 
tradicional. Antiguamente, la felicidad reunía las características de supremo bien y de fin último. Descartes inicia su reforma de los preceptos morales antiguos dejando de aceptar que la felicidad es tanto el bien supremo como el fin último. Seguidamente, Descartes distingue con claridad el concepto de bien supremo del concepto de felicidad, porque, de forma innovadora, Descartes propone una felicidad que no es propiamente un bien, sino que es la emoción de la mente que se genera una vez se alcanza el bien supremo. De la misma manera, Annas (2011) considera que una concepción de la felicidad como emoción no era aceptable en las teorías antiguas. La teoría de Descartes no discute si "your life as a whole which is said to be happy or not" (Annas, 2000, p. 40), tal y como lo pensaban los antiguos. Descartes no usa la expresión "vita beata", una vida feliz, sino que habla de "vivere beate", vivir felizmente o vivir teniendo la mente completamente contenta y satisfecha (Descartes a Élisabeth, Egmond, 4 août 1645. AT IV, 264) ${ }^{13}$. Y esto solo será posible viviendo virtuosamente, haciendo el mejor uso de nuestras facultades naturales. Señales claras de la ruptura cartesiana con la tradición se encuentran en esta distinción entre felicidad y bien supremo y en su caracterización como una emoción placentera de la mente.

\section{La felicidad como fin de nuestras acciones}

Además de establecer una distinción entre la felicidad y el bien supremo, y de proponer una nueva forma de entender el concepto de felicidad, Descartes también ofrece una nueva forma de pensar el fin u objetivo de nuestras acciones. Tradicionalmente, ese objetivo era la felicidad que también ocupaba el lugar del bien supremo. En el modelo eudemonista, la felicidad es el bien perfecto porque siempre es elegida por sí misma y no por otra cosa (Aristóteles, Ética Nicomáquea 1097b1). De esa forma, también ella ocupa el lugar de fin último u objetivo de todas las acciones (Aristóteles, EN, 1097b20). Descartes analiza esos temas de una manera diferente. Para Descartes la virtud, o la firme voluntad de actuar correctamente (Descartes a Christine de Suède, Egmond, 20 novembre 1647. AT $\mathrm{V}, 82$ ), es el mayor bien del individuo porque no hay "aucun autre bien qui me semble si grand, ni qui soit entièrement au pouvoir d'un chacun" (AT V, 83). Si reflexionamos sobre el valor de la virtud, ella siempre será nuestro objetivo porque reconocemos que ella es el mayor bien que podemos alcanzar individualmente, sin asistencia alguna de factores externos. Por eso, ella será apropiadamente el fin de nuestras acciones. Saber que la virtud es el bien más valioso, nos hace apreciarla y nos puede incitar a buscarla. La virtud cartesiana es nuestro fin último porque ella constituye el bien más valioso.

Sin embargo, como la práctica de la virtud siempre viene acompañada por el contentamiento y por la satisfacción, también es posible, según Descartes, considerar a la felicidad como el fin de nuestras acciones. Ella constituye un

${ }^{13}$ En la carta a Élisabeth de enero de 1646, Descartes usa la expresión "vie heureuse" (AT IV, 357). 
atractivo adicional para incitarnos a buscar la virtud, es como un premio de una competición (Descartes a Élisabeth, Egmond, 18 août 1645. AT IV, 277). La práctica de la virtud necesariamente produce contentamiento y eso hace que la virtud sea "much more desirable" (Rutherford, 2004, p. 184). Así, contrariando una vez más el modelo tradicional que propone solo un fin último de nuestras acciones, Descartes ofrece dos fines últimos: virtud y felicidad. Como se expuso anteriormente, la propuesta cartesiana de una felicidad, que puede ser considerada como un premio para incentivar la práctica de la virtud, es otra indicación de que el autor francés no está pensando la béatitude en los términos del modelo antiguo.

Como se mencionó, la virtud tiene valor en sí misma, es el mayor bien del individuo, y nuestro interés en buscarla está plenamente justificado. No obstante, no se debe pensar que la virtud es únicamente un medio para sentir el placer que es la felicidad" ${ }^{14}$. Our final goal ought to be to attain the supreme good; contentment will come to us as a result" (Schneewind, 1998, p. 190). La felicidad aparece como un atractivo para fortalecer todavía más nuestra búsqueda de la virtud. Descartes afirma que nuestras inclinaciones naturales "nous portent ordinairement à suivre la volupté" (Descartes a Élisabeth, Egmond, 18 août 1645. AT IV, 273) y nos imprimen un deseo por la felicidad, el máximo placer que podemos gozar en esta vida. Ese deseo natural de felicidad nos motiva fuertemente a decidir hacer buen uso de nuestras facultades, es decir, nos motiva a practicar la virtud. Nuestra naturaleza, por medio del placer, nos guía hacia nuestra excelencia individual. Descartes presenta la béatitude como premio para la práctica de la virtud y, de esa forma, el deseo natural que conduce a buscar la felicidad, puede ser entendido como un deseo natural por alcanzar la virtud. Para Descartes, el deseo natural de felicidad, que está presente en todos los individuos, dirige nuestra atención en dirección de la virtud. Cuando entendemos la unión entre felicidad y virtud, podemos ver que nuestro deseo natural de felicidad nos conduce también a desear la virtud. La virtud no es un simple medio para alcanzar la felicidad; realmente, dice Descartes, la felicidad nos motiva a desear mucho más la práctica de la virtud ${ }^{15}$.

Esa caracterización de la felicidad como una emoción de la mente y la distinción entre felicidad y bien supremo marcan dos aspectos que diferencian la teoría cartesiana de las teorías eudemonistas antiguas. Descartes propone algunas nuevas definiciones de los conceptos fundamentales de la teoría de la felicidad y establece nuevas relaciones entre ellos para lograr mayor claridad en la comprensión de los mismos. Realmente, Descartes fue un crítico de las teorías morales antiguas, especialmente de la teoría estoica. En el Discurso afirma que

\footnotetext{
${ }^{14}$ Véase Marshall, 1998, p. 68.

${ }^{15}$ Nuestra naturaleza usa el placer como motivación para alcanzar un bien y no lo presenta como un bien adicional. La virtud no puede ser considerada como un medio para alcanzar otro bien porque el placer que ella produce no es un bien y porque no hay, en relación al individuo, algún otro bien de mayor valor.
} 
los antiguos paganos "elevan bien alto las virtudes, y las hacen aparecer como estimables por encima de todas las cosas que hay en el mundo, pero no enseñan suficientemente a conocerlas" (AT VI, 8). En la carta a Élisabeth del 4 de agosto de 1645, Descartes expone una crítica similar cuando afirma que Séneca falla por no mostrar los conocimientos requeridos para "faciliter l'usage de la vertu" (AT IV, 267). Por eso, el proyecto moral cartesiano puede ser considerado como un intento de reformar y de mejorar lo que los antiguos enseñaban sobre la felicidad, la virtud y la forma de conducir nuestras vidas. Definir la felicidad como un placer y no como un bien y proponer dos fines últimos son muestra de la reforma cartesiana al modelo antiguo, la cual está basada en una nueva forma de comprender la naturaleza humana.

\section{El modelo nuevo y las teorías tradicionales}

Una vez explicada la forma en la que Descartes se diferencia del modelo tradicional que los antiguos usaban para teorizar sobre la felicidad, vale la pena ver cómo las teorías de "les philosophes païens, touchant le souverain bien et la fin de nos actions" (Descartes a Élisabeth, Egmond, 18 août 1645. AT IV, 275) son interpretadas desde la perspectiva cartesiana. Con su nuevo modelo, se podrían "surmonter les divergences, superficielles selon Descartes, entre péripatéticiens, stoïciens et épicuriens" (Rodis-Lewis, 1998, p. 43).

Descartes menciona que las tres principales teorías antiguas son, en su opinión, la teoría de Aristóteles, la teoría de Zenón ${ }^{16}$ y la teoría de Epicuro. Tradicionalmente consideradas como teorías rivales e incompatibles (Annas, 2000, pp. 36-52), ellas serán interpretadas favorablemente por Descartes para mostrar cómo todas ellas pueden "être reçues pour vraies et accordées entre elles" (Descartes a Élisabeth, Egmond, 18 août 1645. AT IV, 275-276). Eso es posible gracias a la reforma cartesiana del modelo tradicional antiguo. Recuérdese que para tales teorías el bien supremo, el fin de las acciones y la felicidad, convergía en una única cosa: la mejor forma de vida posible; no obstante, Descartes distingue esos tres conceptos y establece nuevas relaciones entre ellos.

Para empezar, la interpretación cartesiana de la teoría aristotélica. Según Descartes, Aristóteles establece que el bien supremo es el agregado de "toutes les perfections, tant du corps que de l'esprit" (Descartes a Élisabeth, Egmond, 18 août 1645. AT IV, 275). Pero Descartes no acepta tal definición del bien supremo porque, para él, esa definición corresponde realmente al bien supremo de "toute la nature humaine en général" (AT IV, 276), y en su teoría de la felicidad solo

\footnotetext{
${ }^{16}$ Zenón de Citio, fundador de la escuela estoica y figura que Descartes usa como representante de esa corriente filosófica. Como mostré, Descartes también se refiere a los estoicos romanos, los cuales no siempre reproducen fielmente las concepciones de la escuela griega original.
} 
está considerando el bien supremo del individuo. El supremo bien de Aristóteles corresponde a lo que Descartes entiende como el bien supremo de "tous les hommes ensemble est un amas ou un assemblage de tous les biens, tant de l'âme que du corps et la fortune, qui peuvent être en quelques hommes" (Descartes a Christine de Suède, Egmond, 20 novembre 1647. AT V, 82 ${ }^{17}$. Ese bien supremo pertenece a "le plus accompli de tous les hommes" y está compuesto de "toutes les perfections dont la nature humaine est capable" (Descartes a Élisabeth, 18 août 1645. AT IV, 276). Sin embargo, la definición aristotélica no le es muy útil, pues Descartes en su exposición sobre la felicidad realmente estudia el bien supremo del individuo, esa perfección de las fuerzas propias del individuo que se logra sin asistencia externa.

Descartes nota que la fortuna tiene incidencia en la felicidad aristotélica. El bien supremo aristotélico se compone, en parte, del conjunto de bienes de la fortuna, los cuales no tienen lugar ni en la virtud ni en la béatitude cartesianas. Según la opinión de Aristóteles, la buena fortuna es necesaria para alcanzar una vida feliz. En su Ética Nicomáquea, afirma que:

Todos creen que la vida feliz es agradable y con razón tejen el placer con la felicidad, pues ninguna actividad perfecta admite trabas y la felicidad es algo perfecto. Por eso, el hombre necesita de los bienes corporales y de los externos y de la fortuna, para no estar impedido por la carencia de ellos. (1153b15-19)

Para Aristóteles, una dosis de buena suerte es necesaria para la vida feliz ${ }^{18}$, y aunque Descartes reconozca que los bienes de la fortuna pueden darnos una clase de contentamiento (Descartes a Élisabeth, Egmond, 4 août 1645. AT IV, 264), él no piensa que las personas necesiten de tales bienes para lograr la felicidad. Evidentemente, sentimos gozo cuando nos suceden cosas favorables, inclusive cuando ellas dependen de causas más allá de nuestro poder. Cuando tenemos buena suerte y recibimos los bienes de la fortuna sentimos placer por poseer esos bienes. Sin embargo, cuando Descartes habla de felicidad, hace referencia al contentamiento producido por causas que están en nuestro interior ${ }^{19}$, particularmente el ejercicio de la virtud, y no está refiriéndose a ese contentamiento producido por el favor de la fortuna. Así, Descartes rechaza la opinión aristotélica sobre la necesidad de los bienes exteriores para vivir felizmente.

\footnotetext{
${ }^{17}$ En esa carta, Descartes expone una distinción entre tres tipos de bien supremo: Dios (el supremo bien en sí mismo), el conjunto de todos los bienes de la mente, del cuerpo y de la fortuna (el supremo bien de todos los hombres juntos) y la virtud (el supremo bien del individuo) (AT V 82). Toda la discusión que presenté hasta este punto trata sobre el supremo bien del individuo.

${ }^{18}$ Véase, Ética Nicomáquea, 1099b3-4, 1100b5-10.

${ }^{19}$ La felicidad cartesiana es una emoción interior o un placer intelectual, es decir, un placer producido por la acción misma del alma.
} 
Por eso, según Descartes, el hombre sabio que goza del favor de la fortuna realmente no es más feliz que el sabio que sufre infortunios. Como la posesión de los bienes de la fortuna produce placer,

Il est certain qu'un homme bien né, qui n'est point malade, qui ne manque rien, et qui avec cela, est aussi sage et aussi vertueux qu'un autre qui est pauvre, malsain et contrefait, peut jouir d'un plus parfait contentement que lui. (Descartes a Élisabeth, Egmond, 4 août 1645. AT IV, 264)

No se puede ignorar que aquí Descartes parece sugerir la posibilidad de una felicidad mayor o más perfecta que la que proviene únicamente del ejercicio de la virtud; pero para el filósofo francés no existe ningún placer más dulce ni más estable que el contentamiento que proviene de la práctica de la virtud. Por lo que, aquí no está hablando de un placer más perfecto que la béatitude, sino se está refiriendo a un mayor número de bienes que constituyen un mayor número de fuentes de emociones placenteras. El hombre sabio y dichoso posee más bienes que el sabio que no cuenta con el favor de la fortuna, y tiene acceso a más fuentes de gozo, a más perfecciones. A pesar de esto, en relación a la perfección que más nos debe importar, el bien supremo individual, los dos están en iguales condiciones. Por eso, Descartes afirma:

Je ne doute point que les plus pauvres et les plus disgraciés de la fortune ou de la nature ne puissent être entièrement contents et satisfaits aussi bien que les autres, encore qu'ils ne jouissent pas de tan de biens. (Descartes a Élisabeth, Egmond, 4 août 1645. AT IV, 264-265)

El sabio rico y el sabio pobre hacen buen uso de su voluntad, tienen control sobre sus deseos y son igualmente virtuosos y felices. La única diferencia entre tales sabios se encuentra en el acceso a los bienes de la fortuna, y como ninguno de estos bienes puede producir un placer mayor que la béatitude, el sabio dichoso no experimenta una felicidad mayor ${ }^{20}$. Este sabio solo tiene numerosos bienes que le permiten vivir más cómodamente, mas no logra ser más feliz que el sabio pobre. El sabio afortunado está más cerca de alcanzar el bien de todos los seres humanos, ese "assemblage de tous les biens, tant de l'âme que du corps et la fortune" (Descartes a Chistine de Suède, Egmond, 20 novembre 1647. AT V, 82). Y este sabio es el hombre feliz aristotélico, tal y como Descartes entiende la teoría de Aristóteles. No obstante, para el filósofo francés, la felicidad consiste en otra cosa. El sabio afortunado no supera en felicidad al sabio pobre, y como Aristóteles no puede reconocer la felicidad del sabio desafortunado, Descartes afirma que no consiguió entender bien lo que era la felicidad verdadera.

\footnotetext{
20 Descartes ha diferenciado claramente la dicha (I'heur) de la felicidad verdadera (béatitude) (Descartes a Élisabeth, Egmond, 4 août 1645. AT IV, 264) y al ser de naturalezas diferentes y provenir de fuentes diferentes, la primera no podría aumentar el grado de la última, no podría hacerla "más perfecta". El acceso a los bienes de la fortuna solo aumenta el número de fuentes de placer que puede experimentar una persona.
} 
Así pues, queda claro que Descartes y Aristóteles tienen dos nociones diferentes de felicidad. El primero considera que la béatitude es una emoción placentera de la mente y el segundo piensa que la felicidad es un tipo de vida en la cual la práctica de las virtudes es acompañada por los bienes de la fortuna. Descartes mismo es consciente de esa diferencia y por eso no se ocupa demasiado en el análisis de la teoría del Estagirita.

En el caso de Epicuro, Descartes interpreta que él afirmó que el supremo bien o el fin de nuestras acciones es el placer. El filósofo francés considera que Epicuro acertó al poner el placer como fin de nuestras acciones. Para Descartes, la felicidad, que es un placer intelectual, puede, con razón, ser considerada como el fin de nuestras acciones. Descartes interpreta favorablemente la doctrina de Epicuro al considerar que, cuando el filósofo griego se refiere a la voluptuosidad, se refiere realmente al placer en general, es decir, al contentamiento de la mente (AT IV, 277). Tanto Descartes como Epicuro entienden que las acciones loables producen placer en la mente, pues para Epicuro no es posible "vivir placenteramente sin vivir sensata, honesta y justamente, ni vivir sensata, honesta y justamente sin vivir con placer" (Laercio, 2016, p. 617) ${ }^{21}$. Descartes y Epicuro reconocen que el placer puede guiarnos hacia la consecución del bien.

Epicuro, como Descartes, conecta la virtud con el placer; para este filósofo griego también es claro que las virtudes "están unidas naturalmente al vivir placentero y la vida placentera es inseparable de ellas" (Laercio, 2016, p. 617). Para Descartes, esa conexión entre virtud y placer no es muy conocida ni aceptada. La causa de la dificultad general para aceptar esa conexión, es la mala fama del placer. Descartes afirma "qu'on attribue souvent le nom de volupté à de faux plaisirs, qui sont accompagnés ou suivis d'inquiétude, d'ennuis et de repentirs" y que por ello "plusieurs ont cru que cette opinion d'Épicure enseignait le vice" (Descartes a Élisabeth, Egmond, 4 août 1645. AT IV, 276-277)22.

Descartes entiende el placer como una motivación que nos lleva a desear más aquello que consideramos bueno. El placer es el goce que el alma tiene cuando posee un bien. Por eso, cuando buscamos el placer asociado a un bien, tenemos un motivo adicional para poseer dicho bien. Esta conexión cartesiana entre la posesión de un bien y el placer permite que la felicidad sea vista como uno de los fines de nuestras acciones y como una guía natural que nos conduce a realizar acciones virtuosas. El conocimiento del valor de la virtud nos hace apreciarla y valorarla, y "la seule connaissance de notre devoir nous pourrait obliger à faire de

\footnotetext{
${ }^{21}$ Vidas y opiniones de los filósofos ilustres (D.L., X, 132).

${ }^{22}$ Epicuro mismo conocía esas críticas a su doctrina. Pero, como Descartes bien nota, el filósofo griego no se refería a los "placeres de los viciosos o a los que residen en la disipación" (Laercio, 2016, p. 617) (D.L., X, 131).
} 
bonnes actions" 23 (Descartes a Élisabeth, Egmond, 4 août 1645. AT IV, 276). Sin embargo, como la práctica de la virtud produce placer, dicho placer es tomado como una motivación adicional para buscar el bien supremo. Este placer, la felicidad, es como el premio que se ofrece en una competencia de tiro al blanco, es la motivación que nos conduce a realizar alguna acción. Así como el premio no puede ser ganado sin mirar el blanco y sin intentar alcanzarlo, la felicidad no puede ser lograda sin el esfuerzo de ejecutar la virtud. Y los que ven el blanco, no se sienten tan inducidos a alcanzarlo si no saben que se ofrece un premio.

De forma similar, dice Descartes, "la vertu, qui est le blanc, ne se fait pas fort désirer, lorsqu'on la voit toute seule; et le contentement, qui est le prix, ne peut être acquis, si ce n'est qu'on la suive" (Descartes a Élisabeth, Egmond, 4 août 1645. AT IV, 277). La sola consideración del valor de la virtud, nos conduce normalmente a que sintamos amor por ella (Pasiones, a. 56. AT XI, 374) pero no necesariamente deseo. Para excitar en nosotros el deseo por la virtud, debemos considerar también que es provechoso para nosotros adquirir ese bien (Pasiones, a. 57. AT XI, 375), debemos querer la presencia de dicho bien (Pasiones, a. 86), esto es, practicar la virtud. Cuando nuestra naturaleza nos lleva a seguir el placer (AT IV, 273) nos indica que para poder alcanzar dicho placer debemos procurar aquello que consideramos bueno. Así, cuando buscamos un placer, deseamos dos cosas: la posesión del bien y el placer que este genera. Por eso, el deseo natural por la felicidad nos lleva a desear la virtud, nos guía a querer adquirir la virtud, o, en otras palabras, nos conduce a ejecutar acciones virtuosas. El deseo que todos los seres humanos tenemos de ser felices es un incentivo natural para que cada individuo busque con empeño la excelencia de su naturaleza ${ }^{24}$.

La virtud es atractiva por ella misma, su valor es enorme y conocerlo nos puede inducir a ejecutar buenas acciones. Pero, como se imagina normalmente que la virtud y el placer se oponen, es normal pensar que la virtud es muy difícil de practicar. Cuando entendemos que la acción virtuosa está acompañada por el placer, el contento que el ejercicio de la virtud produce se presenta como un premio que nos motiva más a seguirla. Sin embargo, Descartes no considera que la virtud sea únicamente un medio para alcanzar el placer ni que el placer pueda ser considerado como un bien. En estos puntos la teoría cartesiana se aparta de la doctrina de Epicuro, para el filósofo griego, el bien supremo es el placer y solo escogemos la virtud para alcanzar ese bien supremo, como un bien intermedio, así

\footnotetext{
${ }^{23}$ Esto sucede particularmente en individuos con "almas fuertes", los cuales usualmente determinan sus acciones siguiendo sus "juicios firmes y determinados respecto al conocimiento del bien y del mal" (Pasiones, a. 48. AT XI, 367).

${ }^{24}$ Aunque sea muy fácil "creer que todas las almas que Dios pone en nuestros cuerpos no son igualmente nobles y fuertes" (Pasiones, a. 161. AT XI, 453) y que, por eso, existan muchas diferencias entre los individuos (Discurso. AT VI, 2), Descartes reconoce que el deseo de ser felices está presente en todos. Y es un deseo lícito que la naturaleza imprime en cada uno de nosotros porque, a pesar de que existan almas más fuertes que otras, todos los seres humanos tienen la posibilidad de hacer buen uso de su libertad y lograr la virtud.
} 
como buscamos el medicamento para lograr la salud (Laercio, 2016, p 619) 25,26. Por esta razón, Descartes considera que Epicuro no enseña la virtud (Descartes a Élisabeth, Egmond, 4 août 1645. AT IV, 277), pues si realmente la enseñara, Epicuro diría que la virtud es el bien supremo, que se busca por sí mismo, y entendería que la búsqueda del placer es la motivación natural que nos lleva a practicar la virtud y no un bien propiamente.

Finalmente, Descartes interpreta que la posición de Zenón indica que el bien supremo es la virtud; asimismo, él considera que el fundador de la escuela estoica entiende ese bien supremo como el mayor bien que "chaque homme en son particulier peut posséder" (Descartes a Élisabeth, Egmond, 4 août 1645. AT IV, 276). Descartes concuerda con Zenón en la identificación del bien supremo del individuo con la virtud y en su caracterización como el único bien "qui dépende entièrement de notre libre arbitre" (AT IV, 276). No obstante, él no acepta que los estoicos separen totalmente la virtud del placer, eso es una muestra del desconocimiento de nuestra naturaleza como seres humanos (AT IV, 273).

Por esta razón, Descartes denuncia que la virtud estoica es tan enemiga del placer, que su práctica se torna demasiado difícil y poco atractiva. Para él, "la plus grande félicité de l'homme dépend de ce droit usage de la raison" (Descartes a Élisabeth, Egmond, 4 août 1645. AT IV, 267), lo cual constituye la virtud. Sin embargo, según Descartes, los estoicos niegan la posibilidad de vincular la virtud con el placer. Por eso, Zenón recibe la crítica cartesiana: "Mais il a représentée cette vertu si sévère et si ennemie de la volupté" que solo "des mélancoliques, ou des esprits entièrement détachés du corps" podrían practicarla (Descartes a Élisabeth, Egmond, 18 août 1645. AT IV, 276). Para Descartes, esto es una clara muestra del desconocimiento de los estoicos de la verdadera naturaleza humana, por eso, considera que la definición estoica de la virtud no es adecuada ${ }^{27}$.

Para Descartes, la insistencia del estoicismo en separar la virtud del placer es la más clara muestra de que esta escuela no conoce adecuadamente la naturaleza humana. Si la virtud es un bien, debe producir un contentamiento en la mente

\footnotetext{
${ }^{25}$ Vidas y opiniones de los filósofos ilustres (D.L., X, 138).

${ }^{26}$ Descartes es sarcástico cuando señala que si él supiese que "le souverain bien fût la joie, je ne douterais point qu'on en dût tâcher de se rendre joyeux, à quelque prix que ce pût être, et j'approuverais la brutalité de ceux qui noient leurs déplaisirs dans le vin, ou les étourdissent avec du pétun" (Descartes a Élisabeth, Egmond, 6 octobre 1645. AT IV, 305). Es clara la crítica cartesiana a los hombres que ubican al placer como el bien supremo en la vida. Esa actitud, además de estar basada en un error, porque el placer no es realmente un bien, no puede mantenerse por mucho tiempo. En algún momento, esa búsqueda ciega del placer llevará a encontrarse en circunstancias desventajosas o se tornará imposible de realizar.

${ }^{27}$ Para Descartes, el verdadero ser humano consiste en una estrecha unión de alma y cuerpo (Discurso. AT VI, 59). Además, Descartes denuncia que la diversidad de definiciones de la virtud que Séneca ofrece en De Vita Beata es señal de que el estoico "n'a pas clairement entendu ce qu'il voulait dire" (Descartes a Elisabeth, Egmond, 18 août 1645. AT IV, 272-275).
} 
de quien la practique, porque el alma "no recibe ningún otro fruto de todos los bienes que posee; y mientras no disfrute ninguna alegría de ellos, puede decirse que no disfruta de ellos más que si no los poseyera" (Pasiones, a. 91. AT XI, 396-397). Si quien practica la virtud no recibe un placer, dicho individuo se encontraría en la misma situación de una persona que no practica la virtud. Según el pensamiento cartesiano, si los estoicos niegan el placer que siente el individuo que actúa virtuosamente, niegan también que la virtud sea un bien. Por eso, Descartes considera que esa concepción estoica de la virtud no refleja la verdadera excelencia de la naturaleza humana.

A partir de la nueva teoría de felicidad que Descartes propone, es posible resolver la oposición de las tres principales teorías de felicidad de los filósofos paganos. La solución es simple: Aristóteles, Zenón y Epicuro no hablan de lo mismo. Por eso, la oposición entre sus doctrinas solo es aparente. Para Descartes, los tres se expresan correctamente. Aristóteles teoriza sobre el bien supremo del género humano, Zenón nombra cuál es el bien supremo del individuo ${ }^{28}$, y Epicuro indica que el placer puede ser considerado como el fin de nuestras acciones. De esta manera, ninguno contradice al otro.

Descartes reconoce que su teoría sobre la felicidad tiene puntos de contacto con las teorías de Epicuro y Zenón (AT V, 83), por lo que se debe explicar con claridad cuáles son esos acuerdos. La concertación entre Epicuro y Descartes consiste en identificar a la felicidad como una emoción placentera y que puede ser considerada con razón como el fin de nuestras acciones; a pesar de esto, el filósofo francés no acepta que el placer sea un bien y mucho menos que sea el bien supremo. Por otro lado, Descartes y Zenón entienden que el bien supremo es la virtud, la excelencia de nuestra naturaleza, y reconocen que ella es el único bien que está siempre en nuestro poder; sin embargo, difieren en el contenido y en la base de la definición de nuestra excelencia. Además, Descartes no acepta la identificación de la virtud con la felicidad, ni la negación radical estoica de una conexión de la virtud con el placer.

De nuevo, se encuentra que la felicidad cartesiana, una emoción placentera de la mente producto del ejercicio del mayor bien al que podemos aspirar como individuos, la virtud o la perfección de nuestras capacidades naturales, no es totalmente compatible con los modelos eudemonistas antiguos. Esto se debe principalmente a que Descartes entiende la naturaleza humana, base de toda la teoría sobre la virtud y la felicidad, de forma diferente a la tradición griega. En ese sentido, Descartes presenta una nueva forma de entender algunos aspectos claves en la comprensión tradicional de la felicidad, una concepción moderna de felicidad.

${ }^{28}$ Aunque no lo define adecuadamente. 


\section{Referencias}

Annas, J. (2000). Ancient Philosophy. A Very Short Introduction. Oxford University Press.

Annas, J. (2011). Intelligent Virtue. Oxford University Press.

Aristóteles (1985). Ética nicomáquea. Ética eudemia. (J. Pallí Bonet, trad.). Gredos.

Cottingham, J. (1998). Philosophy and the Good Life. Reason and the Passions in Greek, Cartesian, and Psychoanalytic Ethics. Cambridge University Press. https://doi.org/10.1017/CBO9780511612237

Descartes, R. (1996). Oeuvres de Descartes. En C. Adam \& P. Tannery. (Eds.). Librarie Philosophique J. Vrin.

Descartes, R. (1999). Discurso del método. La búsqueda de la verdad mediante la luz natural (V. Florián, trad.). Panamericana.

Descartes, R. (2010). Las pasiones del alma (J. A. Martínez \& P. Andrade, trads.). Tecnos.

Faye, E. (1998). Philosophie ou la perfection de l'homme. De la Rennaissance à Descartes. Librarie Philosophique J. Vrin.

Furetière, A. (1690). Dictionnaire universel. Arnout \& Reinier Leers.

Kambouchner, D. (2001). Descartes (1596-1659): bonheur et utilité. En A. Caillé, C. Lazzeri \& M. Senellart. (Eds.). Histoire raisonnée de la philosophie morale et politique (pp. 305-310). La Découverte.

Laercio, D. (2016). Vidas y opiniones de los filósofos ilustres. (C. García Cual, trad.). Alianza Editorial.

Leibniz, G. W. (1880). Die philosophischen Schriften. Vol. 4. En C. I. Gerhardt. (Ed.). Weidmannsche Buchhandlung.

Long, A. A. (1996). Stoic Studies. University of California Press.

Long, A. A. (2006). From Epicurus to Epictetus. Studies in Hellenistic and Roman Philosophy. Oxford University Press.

Marshall, J. (1998). Descartes's Moral Theory. Cornell University Press. 
Platón (1983). Diálogos. Vol. II. Gorgias. Menéxeno. Eutidemo. Menón. Cratilo. Gredos.

Platón (1986). Diálogos. Vol. III. Fedón. Banquete. Fedro. Gredos.

Rodis-Lewis, G. (1997). Le developpement de la pensée de Descartes. Librarie Philosophique J. Vrin.

Rodis-Lewis, G. (1998). La morale de Descartes. Presses Universitaires de France.

Rutherford, D. (2004). On the Happy Life: Descartes vis-à-vis Seneca. En S. Strange \& J. Zupko (eds.). Stoicism: Traditions and Transformations (pp. 177-197). Cambridge University Press. https://doi.org/10.1017/ CBO9780511498374.011

Schneewind, J. (1998). The Invention of Autonomy. A History of Modern Moral Philosophy. Cambridge University Press.

Séneca (1979). De la vida bienaventurada. En Cicerón \& Séneca. Tratados morales (pp. 407-435). Editorial Cumbre.

Shapiro, L. (2011). Descartes on Human Nature and the Human Good. En C. Fraenkel, D. Perinetti \& J. E. H. Smith. (Eds.). The Rationalists. Between Tradition and Innovation (pp. 13-26). Springer. https://doi.org/10.1007/97890-481-9385-1

Sorell, T. (1993). Morals and Modernity in Descartes. En T. Sorell. (Ed.). The Rise of Modern Philosophy (pp. 273-288). Clarendon Press.

Striker, G. (1990). Ataraxia: Happiness as Tranquillity. The Monist, 73(1), 97-110. https://doi.org/10.5840/monist199073121

Svensson, F. (2015). Non-eudaimonism, the Sufficiency of Virtue for Happiness, and Two Senses of the Highest Good in Descartes's Ethics. British Journal for the History of Philosophy, 23(2), 277-296. http://dx.doi.org/10.1080/096087 88.2014.982508 